\title{
Multiplex PCR to diagnose bloodstream infections in patients after cardiothoracic surgery
}

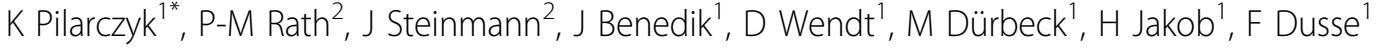 \\ From ESICM LIVES 2015 \\ Berlin, Germany. 3-7 October 2015
}

\begin{abstract}
Introduction
Infectious complications and sepsis are major causes of mortality and morbidity after cardiac surgery. Early detection of the causing microorganisms and prompt initiation of adequate antimicrobial therapy are crucial for patient survival. However, blood culture (BC) as the current diagnostic gold standard suffers from low sensitivity, as well as a reporting delay of approximately 48-72 h. LightCycler SeptiFast (SF) is a real-time multiplex polymerase chain reaction test able to detect 25 common pathogens responsible for bloodstream infections within hours.
\end{abstract}

\section{Objectives}

This single-center retrospective study aimed to compare the performance of SF matched with conventional BC samples and identify predictors for positivity of SF in patients after cardiothoracic surgery.

\section{Methods}

Overall, 279 blood samples from 168 individuals with suspected bloodstream infection were analyzed by both, $\mathrm{SF}$ and BC. Receiver operating characteristic (ROC) curves were generated to determine the accuracy of clinical and laboratory information for the prediction of positive SF results.

\section{Results}

Excluding results attributable to contaminants, 14.7\% $(\mathrm{n}=41)$ of the blood samples were positive using SF and $17.2 \%(\mathrm{n}=48)$ using conventional $\mathrm{BC}(\mathrm{p}=\mathrm{n} . \mathrm{s}$.). In six samples, multiplex-PCR detected more than one pathogen. Among the 47 microorganisms identified by SF, only $11(23.4 \%)$ could be confirmed by BC. SF identified a significantly higher number of gram-negative

'West German Heart and Vascular Center Essen, University Hospital Essen, Department of Thoracic and Cardiovascular Surgery, Essen, Germany Full list of author information is available at the end of the article bacteria than $\mathrm{BC}\left(28\right.$ vs. $\left.11, \chi^{2}=7.97, \mathrm{p}=0.005\right)$. The combination of $\mathrm{BC}$ and SF significantly increased the number of detected microorganism compared to $\mathrm{BC}$ alone (48 (\%) vs. $\left.85(\%), \chi^{2}=13.51, \mathrm{p}<0.001\right)$. C-reactive protein $(21.7 \pm 11.41$ vs. $16.0 \pm 16.9 \mathrm{mg} / \mathrm{dL}, \mathrm{p}=0.009)$, procalcitonine $(28.7 \pm 70.9$ vs. $11.5 \pm 30.4 \mathrm{ng} / \mathrm{dL}, \mathrm{p}=$ $0.015)$ as well as IL-6 $(932.3 \pm 1306.7$ vs. $313.3 \pm 686.6$ $\mathrm{pg} / \mathrm{mL}, \mathrm{p}=0.010$ ) were significantly higher in patients with positive SF result. In addition, incidence of acute kidney injury requiring renal replacement therapy (31 (76\%) vs. $125(53 \%), \mathrm{p}=0.01$ ) was higher in SF positive patients. Using ROC analysis, IL-6 (AUC 0.836, sensitivity $78.6 \%$, specificity $75.9 \%$ for cut off $184 \mathrm{pg} / \mathrm{mL}$ ) as well as C-reactive protein (AUC 0.804, sensitivity $71.4 \%$, specificity $75.9 \%$ for cut-off $15.25 \mathrm{mg} / \mathrm{dL}$ ) showed the best predictive values for positive SF results.

\section{Conclusions}

The PCR-based SeptiFast test is a valuable addition to the traditional blood culture method to rapidly diagnose the etiology of bloodstream infections in patients after cardiothoracic surgery. This applies in particular for individuals with gram-negative bacteremia, organ failure and/or elevated CRP and IL-6-levels.

\section{Authors' details}

'West German Heart and Vascular Center Essen, University Hospital Essen, Department of Thoracic and Cardiovascular Surgery, Essen, Germany.

${ }^{2}$ University Hospital Essen, Institute of Medical Microbiology, Essen, Germany.

Published: 1 October 2015

doi:10.1186/2197-425X-3-S1-A884

Cite this article as: Pilarczyk et al:: Multiplex PCR to diagnose

bloodstream infections in patients after cardiothoracic surgery. Intensive Care Medicine Experimental 2015 3(Suppl 1):A884. (c) 2015 Pilarczyk et al.; This is an Open Access article distributed under the terms of the Creative Commons Attribution License (http:// creativecommons.org/licenses/by/4.0), which permits unrestricted use, distribution, and reproduction in any medium, provided the original work is properly cited. 